\title{
Morphological Characteristics of Bambusa vulgaris and the Distribution and Shape of Vascular Bundles therein ${ }^{1}$
}

\author{
Atmawi Darwis $\mathbb{D}^{2} \cdot$ Apri Heri Iswanto $\mathbb{D}^{3, \dagger}$
}

\begin{abstract}
Bamboo culm comprises internodes and nodes and is tapered from the bottom to the top. Anatomically, bamboo culm comprises vascular bundles and parenchymal base tissue. The gross anatomical structure of a transverse section of any culm internode is determined by the shape, size, arrangement, and number of vascular bundles. The purpose of this research was to examine the morphology of culm and the distribution and shape of vascular bundles in Ampel bamboo (Bambusa vulgaris). Bamboo culms were harvested from the base. Test samples were obtained from a central 2-cm long segment of each internode across the entire length of the culm. Results showed an uneven spread of vascular bundles in the internode cross-section. Transitioning from the outer to the inner layer of the internode, the number of vascular bundles per unit area decreased and their shape was variable. The size of vascular bundles in the middle layer of the internode was greater than that of those in the outer and inner layers. The shape of vascular bundles was circular in the outer layer, which gradually transformed into vertical oval toward the middle layer and horizontal oval toward the inner layer. Vascular bundles were of type III and IV in the bottom of the culm and type III in the middle to the top of the culm.
\end{abstract}

Keywords: Bambusa vulgaris, internode length, morphology of culm, distribution and shape of vascular bundles

\section{INTRODUCTION}

Bamboo grows naturally in tropical and subtropical regions (Gratani et al., 2008). It is a very fast growing plant (Liu et al., 2012), with a uniform culm growth of $60 \mathrm{~mm}$ per day (Bui et al., 2017). Bamboo plants reach maturity and are ready for use within 3-5 years (Troya and $\mathrm{Xu}, 2014)$. In Indonesia, bamboo is mostly cultivated in Java, Bali, and Sulawesi (Widjaja, 2001). It is consumed as a medicine (Kim et al., 2014) as well as food and is also used as a raw material for making furniture, buildings (Kaminski et al., 2016), household equipment, handicrafts (Maulana et al., 2017), and musical instruments (Kang et al., 2017). Additionally, bamboo is one of the most promising alternative raw materials for manufacturing composite panels (Roh et al., 2004). It is more commonly used as a building material in the rural society. Because bamboo is easily available, it is relatively cheap. Bamboo is not only a versatile resource for the livelihoods of

\footnotetext{
${ }^{1}$ Date Received March 25, 2018, Date Accepted June 19, 2018

2 School of Life Sciences and Technology, Institut Teknologi Bandung, Gedung Labtex XI, Jalan Ganesha 10, Bandung 40132, West Java-Indonesia (ORCID: 0000-0002-2130-608X)

${ }^{3}$ Department of Forest Product, Faculty of Forestry, Universitas Sumatera Utara, Padang Bulan, Medan 20155, Indonesia

$\dagger$ Corresponding author: Apri Heri Iswanto (e-mail: apriheri@yahoo.com, ORCID: 0000-0002-4243-1429)
} 
people but also reduces the impact of and adaptation to climate change (Wu et al., 2015).

A total of 143 bamboo species have been reported to grow in Indonesia (Widjaya, 2001). Bamboo plants native to Southeast Asia exhibit a pachymorph rhizome system wherein each rhizome has short internodes and an apex that continues to grow into a culm (Dransfield and Widjaya, 1995). Bamboo culms are usually arranged close together, forming a densely tufted (sympodial) clump. The bamboo clump expands centrifugally, with young culms on the outside surrounding the older culms (Banik, 2015).

Ampel bamboo (Bambusa vulgaris) is a type of bamboo that is easy to find and grows well in Indonesia, particularly in Java. B. vulgaris grows in extreme dry and moist areas and has been reported to grow in waterlogged areas for 2-3 months. This bamboo culm can grow as high as $20 \mathrm{~m}$ (Widjaja, 2001). B. vulgaris grows in clumps and comprises several culms, gradually growing from shoots to mature culms. This bamboo culm is hollow, hard-walled, and conical at the end, indicating a different inner and outer diameter (cavities) and thick walls. The diameter and slat thickness of bamboo culms are determined when considering its use.
Anatomically, bamboo culm comprises vascular bundles and parenchymal base tissue. Vascular bundles comprise fiber caps or sheaths surrounding the conducting elements, including vessels, sieve tubes, and companion cells (Liu et al., 2012), all of which affect bamboo characteristics (Liese, 1998). Reportedly, vascular bundles spread unevenly from the outer to the inner layer of the culm (Li, 2004). Moreover, the shape and size of vascular bundles in the culm are variable.

In the present study, we investigated the morphological characteristics of B. vulgaris culm and the distribution and shape of vascular bundles from the bottom to the top of the culm. The results of this study are invaluable for understanding the anatomical features of $B$. vulgaris and for preparing basic databases for different types of bamboo.

\section{MATERIALS and METHODS}

\subsection{Plant material}

Three-year-old B. vulgaris var. vulgaris samples with green culms were collected from the village of Sayang, District Jatinangor, Sumedang Regency, West Java
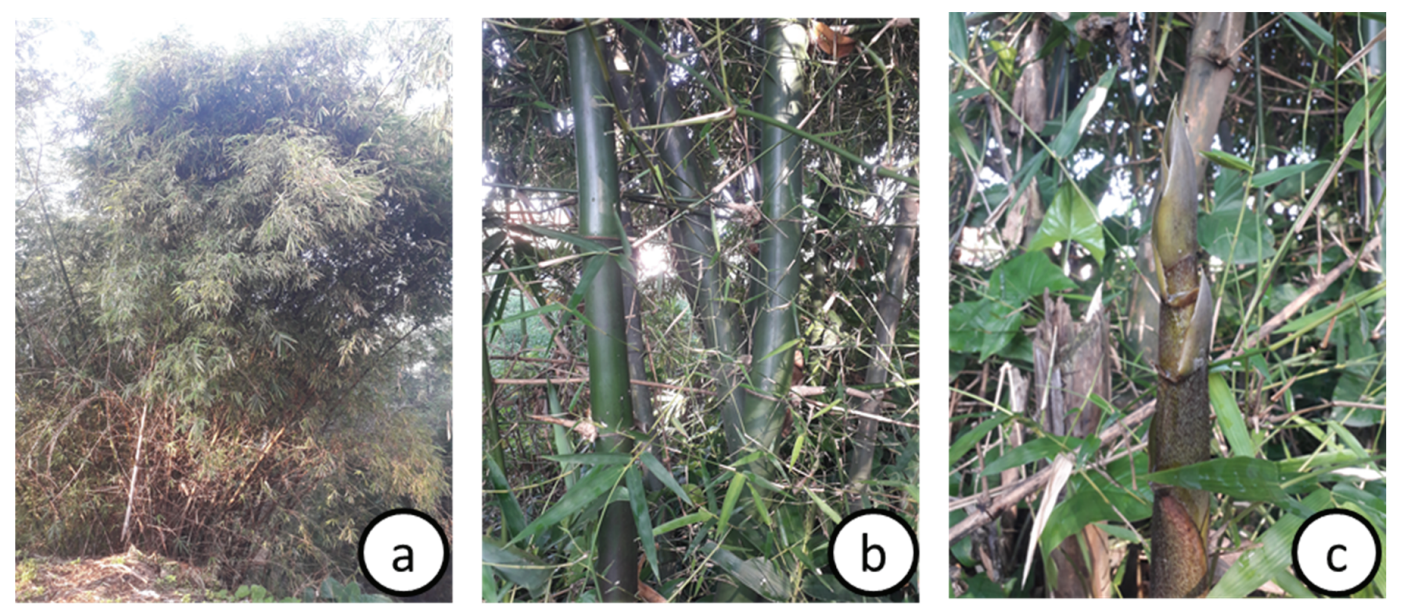

Fig. 1. Images of B. vulgaris var. vulgaris growing in West Java Province, Indonesia. These images show (a) clumps, (b) culms, and (c) shoots of bamboo. 


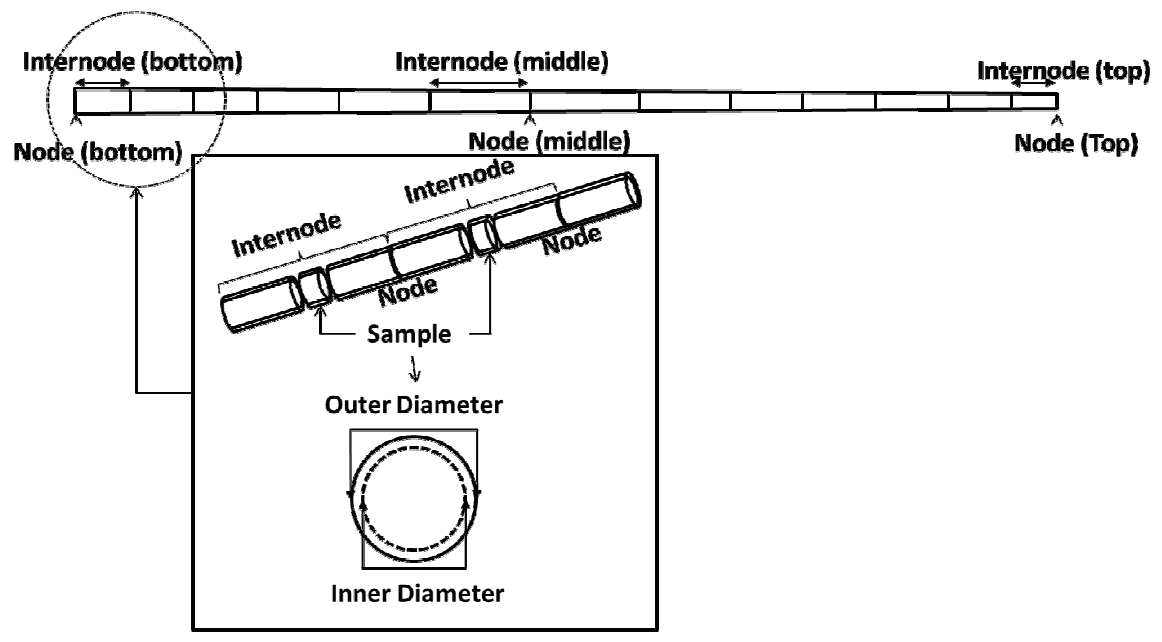

Fig. 2. Schematic representation of morphological culm measurements of b. vulgaris var. vulgaris.

Province, Indonesia (Fig. 1). Bamboo culms were harvested just above the roots, and branches on the culm were subsequently removed to obtain branchless culms.

\subsection{Morphological characterization of bamboo culms}

The length of each bamboo internode was measured from the base to the tip. The outer and inner diameters of each internode were measured from a central 2-cm long column-shaped area. The thickness of bamboo culm wall of each internode was calculated from the difference between the two diameters (Fig. 2).

\subsection{Vascular bundle distribution in bamboo culm cross-section}

To examine the distribution and shape of vascular bundles in bamboo, culm cross-sections were prepared using a sharp knife and observed under a Nikon SMZ 745T stereomicroscope, Nikon Corporation, Tokyo, Japan. Morphological data were analyzed using NIS-Elements v.4.00.00 imaging software. The number of vascular bundles per unit area $\left(\mathrm{VB} / \mathrm{mm}^{2}\right)$ was counted from the outer to the inner layer of the bamboo wall. The shape of vascular bundles was assessed by measuring the radial diameter (R) and tangential diameter $(\mathrm{T})$ of each vascular bundle from the outer layer toward the inner layers. An R/T ratio of 1 indicated circular vascular bundles, whereas $\mathrm{R} / \mathrm{T}$ ratios of $<1$ and $>1$ indicated oval lengthwise tangential and oval lengthwise radial vascular bundles, respectively. Stages of morphological observations of the culm and the distribution and shape of vascular bundles of $B$. vulgaris var. vulgaris are shown in Fig. 3.

\section{RESULTS and DISCUSSION}

\subsection{Morphology of bamboo culm}

Bamboo culm comprises nodes and internodes. Within a culm, the node appears as a diaphragm between the cavities. The internode, which is the region between two consecutive nodes, showed varying lengths. The mid-section of the internode was longer in size than the bottom and top sections (Fig. 4). These data are consistent with those recorded for other bamboo types 


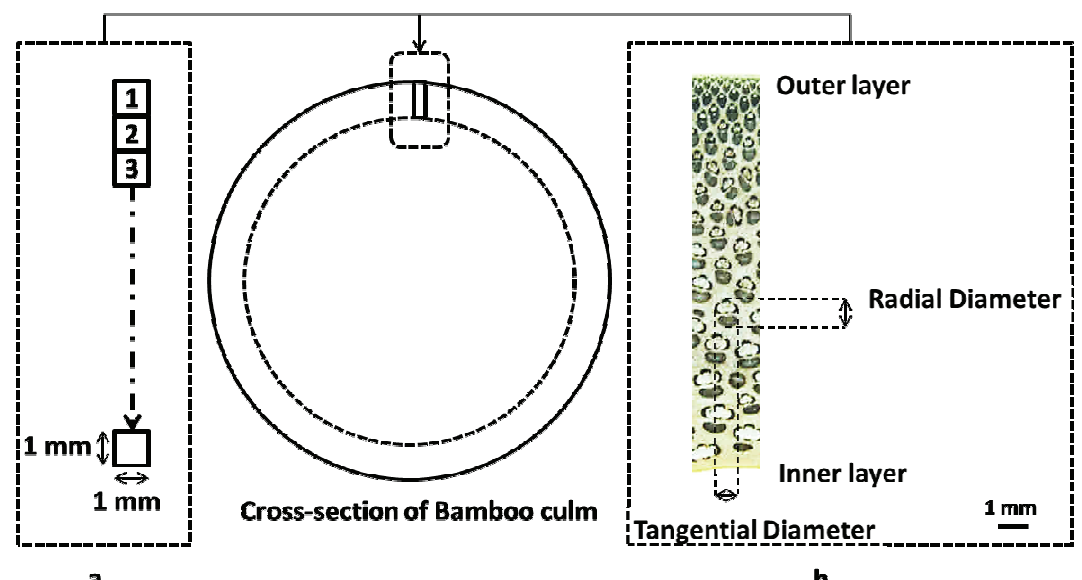

Fig. 3. Measurements of (a) the distribution and (b) shape of vascular bundles in B. vulgaris var. vulgaris.

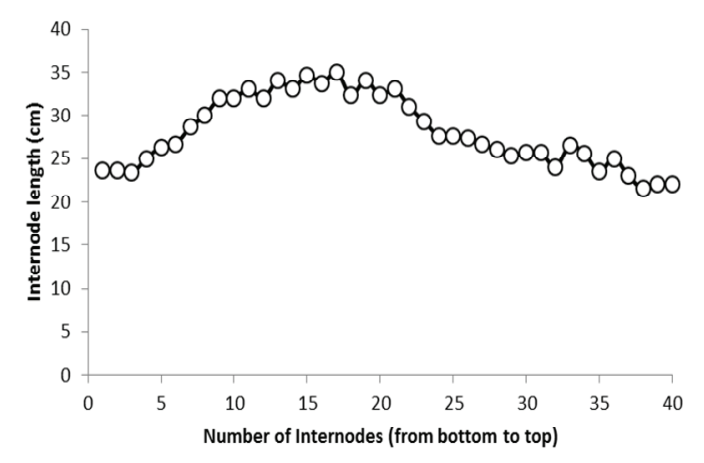

Fig. 4. Internode length of $B$. vulgaris var. vulgaris from the bottom to the top of the bamboo culm.

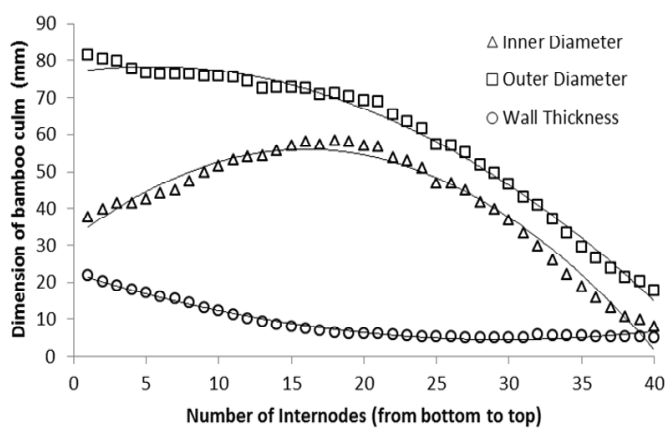

Fig. 5. Internode dimensions of $B$. vulgaris var. vulgaris culm from the bottom to the top.
(Dransfield and Widjaya, 1995). The shortest length has been reported for the lowest internodes of Gigantochloa atter (Marsoem et al., 2015).

Additionally, the outer and inner diameters (cavities) of culm internodes, and consequently, the thickness of the culm wall were variable. The outer diameter of the bamboo culm decreased from the bottom to the top. The inner diameter of the mid-section of the internode was greater than those of the bottom and top sections. A reduction in the outer diameter of the culm from the bottom to the top resulted in the conical shape of the bamboo culm, causing the thickness of the culm wall to decrease from the bottom to the top (Fig. 5). Zakikhani et al. (2017) have reported similar results in other bamboo species.

\subsection{Cross-sectional distribution, type and shape of vascular bundles in bamboo culm}

Being a monocot plant, bamboo culm comprises vascular bundles and parenchymal base tissue. The culm cross-section showed an uneven distribution of vascular bundles. The density of vascular bundles is reportedly 


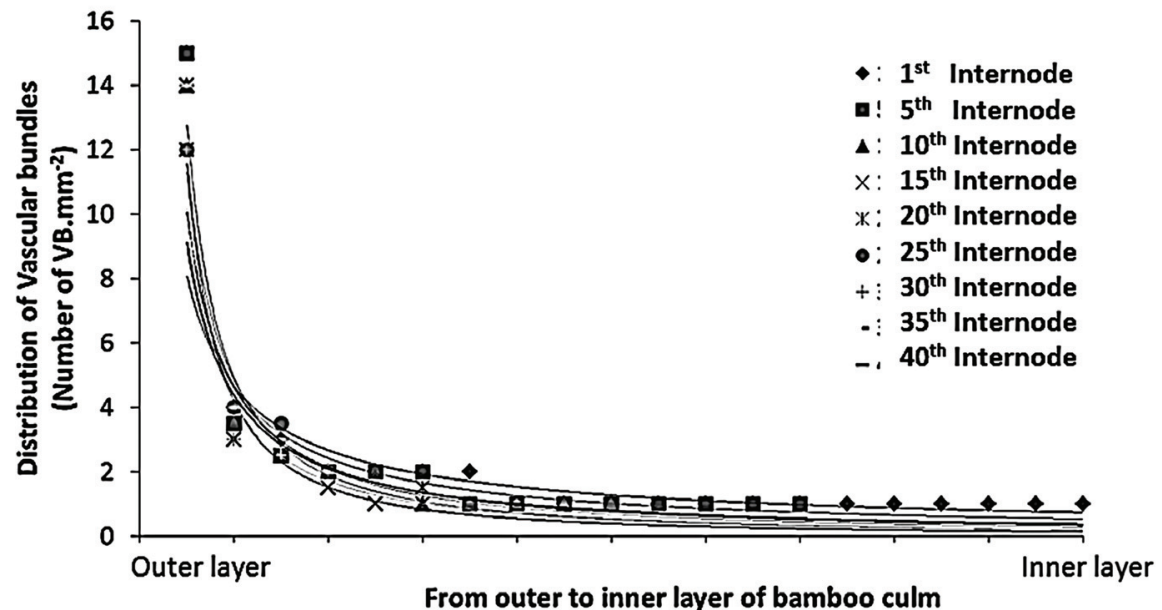

Fig. 6. Distribution pattern of vascular bundles in culm internodes of B. vulgaris var. vulagris from the outer to the inner layer.

higher in the outer layer of the culm than in the inner layer (Jeon et al., 2018). These data are consistent with the results of our study. We showed that the number of vascular bundles per unit area decreases from the outer to the inner layer (Fig. 6), and vascular bundles in the outer layer appear more dense/compact than those in the inner layer (Fig. 7). The number of vascular bundles per unit area of the internode also decreased from the bottom to the top of the culm (Fig. 6). Additionally, vascular bundles in the bottom internodes tended to be smaller in size than those in the top internodes of the bamboo culm (Fig. 7). Thus, the number of vascular bundles per unit area in the bottom internodes was greater than those in the top internodes. The distribution pattern of vascular bundles in bamboo was described as an exponential function, similar to the distribution of vascular bundles in oil palm trunk (Darwis et al., 2013).

Bamboo culm cross-sections showed variability in the type of vascular bundles from the outer to the inner layer. The $1^{\text {st }}, 5^{\text {th }}$, and $10^{\text {th }}$ internodes contained two types of vascular bundles, type III and type IV, whereas the $15^{\text {th }}-40^{\text {th }}$ internodes contained only type III vascular bundles (Fig. 7). Type III vascular bundles typically contain only one fiber sheath at the bottom of the main vascular bundle, whereas type IV vascular bundles contain two fiber sheaths, one above and the other below the main vascular bundle (Liese, 1998). The presence of different types of vascular bundles was influenced by the thickness of bamboo walls, which decreased from the bottom to the top. Varying sizes of vascular bundles in bamboo culm cross-sections have been reported previously, wherein vascular bundles in the outer layer appear smaller than those in the inner layer (Wahab et al., 2009; Mustafa et al., 2011).

In the present study, we measured the shape of vascular bundles as the $\mathrm{R} / \mathrm{T}$ ratio. Vascular bundles were circular in the outer layer and gradually transitioned to an oval shape in the inner layer. With an increase in the value of $\mathrm{R}$, vascular bundles gradually acquired an oval-like vertical shape toward the middle layer. In contrast, an increase in the value of $\mathrm{T}$ induced the vascular bundles to acquire an oval-like horizontal shape toward the inner layer (Fig. 8). Based on the $\mathrm{R} / \mathrm{T}$ ratio, the vascular bundles in the bottom internodes were smaller than those in the top internodes. 


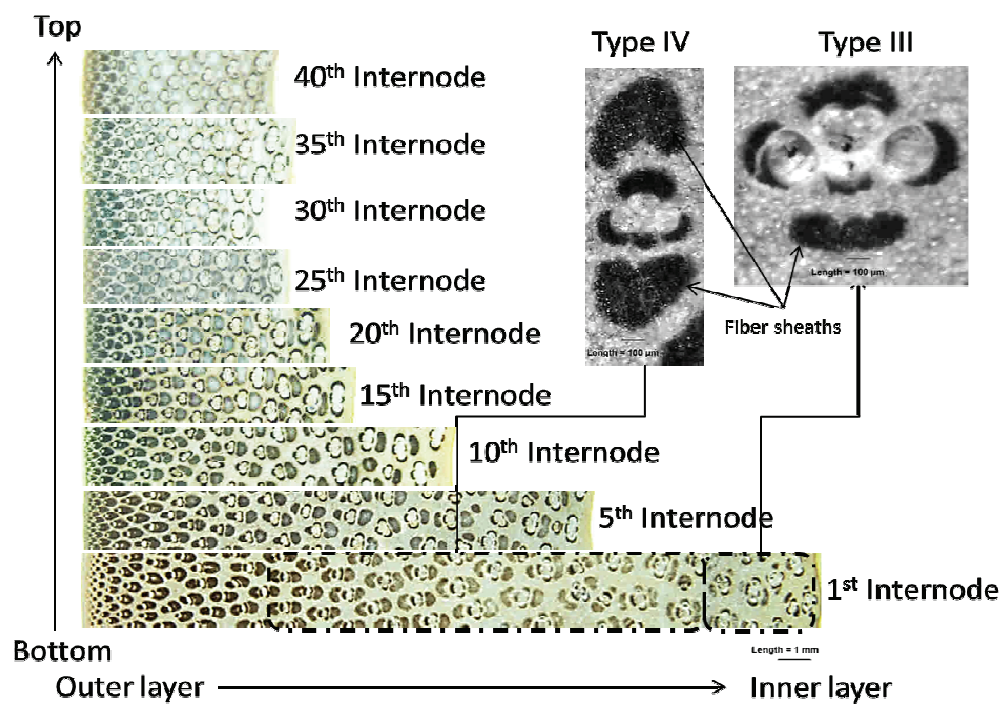

Fig. 7. Micrographs of vascular bundles in culm internodes of $B$. vulgaris var. vulgaris from the outer to the inner layer.

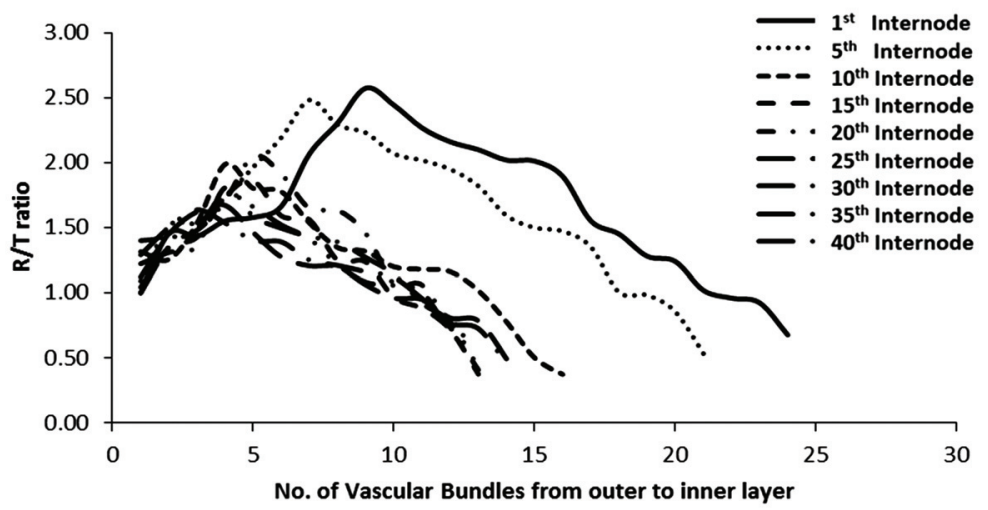

Fig. 8. Ratio of radial diameter $(R)$ to tangential diameter $(T)$ of vascular bundles from the outer to the inner layer of internode cross-sections of $B$. vulgaris var. vulgaris.

\section{CONCLUSION}

Bamboo culm compound internodes showed variable lengths and diameters. The length of the internode increased from the bottom to the mid-section and then decreased toward the top. The conical shape of the culm indicated that the outer diameter decreased from the bottom of the culm to the top. The inner diameter of the mid-section of the bamboo culm decreased both toward the bottom and the top, resulting in decreased 
thickness of the bamboo culm.

Vascular bundles, one of the main constituents of bamboo culm, were unevenly distributed at the crosssections. Those in the outer layer appeared more dense/compact than those in the inner layer, and their distribution showed an exponential function graph. According to the $\mathrm{R} / \mathrm{T}$ ratio, the shape of vascular bundles in culm cross-sections varied from circular to oval. Additionally, bamboo culms contained type III and IV vascular bundles at the bottom and type III vascular bundles at the middle and top.

\section{REFERENCES}

Banik, R.L. 2015. Morphology and growth. In: Bamboo: The plant and its uses. Ed. by Liese W and Kohl M., Springer International Publishing. Switzerland. pp. 4389.

Bui, Q.B., Grillet, A.C., Tran, H.D. 2017. A bamboo treatment procedure: effects on the durability and mechanical performance. Sustainability 9(9): 1444.

Darwis, A., Nurrochmat, D.R., Massijaya, M.Y., Nugroho, N., Alamsyah, E.M., Bahtiar, E.T., Safe’I, R. 2013. Vascular bundle distribution effect on density and mechanical properties of oil palm trunk. Asian Journal of Plant Sciences 12(5): 208-2013.

Dransfield, S., Widjaya, E.A. 1995. Plant Resources of South East Asia No 7: Bamboos. Backhuys Publishers, Leiden. pp. 189.

Gratani, L., Crescente, M.F., Varone, L., Fabrini, G., Digiulio, E. 2008. Growth pattern and photosynthetic activity of different bamboo species growing in the Botanical Garden of Rome. Flora 203(1): 77-84.

Jeon, W.S., Kim, Y.K., Lee, J.A., Kim, A.R., Darsan, B., Chung, W.Y., Kim, N.H. 2018. Anatomical characteristics of three korean bamboo species. Journal of the Korean Wood Science and Technology 46(1): 29-37.
Kaminski, S., Lawrence, A., Trujillo, D. 2016. Structural use of bamboo: Part 1: Introduction to bamboo. The Structural Engineer 94(8): 40-43.

Kang, C.W., Chung, W.Y., Han, J.O., Kang, H.Y. 2017. High-temperature drying of bamboo tubes pretreated with polyethylen glycol solution. Journal of the Korean Wood Science and Technology 45(2): 139-146.

Kim, J.S., Lee, H.C., Jo, J.S., Jung, J.Y., Ha, Y.L., Yang, J.K. 2014. Evaluation of antioxidant and anticancer activity of steam extract from the bamboo species. Journal of the Korean Wood Science and Technology 42(5): 543-554.

Li, X. 2004. Physical, chemical, and mechanical properties of bamboo and its utilization potential for fiberboard manufacturing. Ph.D. Thesis, Louisiana State University, USA.

Liese, W. 1998. The anatomy of bamboo culms. Technical Report, INBAR, Beijing, China.

Liu, D., Song, J., Anderson, D.P., Chang, P.R., Hua, Y. 2012. Bamboo fiber and its reinforced composites: structure and properties. Cellulose 19: 1449-1480.

Marsoem, S.N., Setiaji, F., Kim, N.H., Sulistyo, J., Irawati, D., Nugroho, W.D., Pertiwi, Y.A.B. 2015. Fiber morphology and physical characteristics of Gigantochloa atter at three different ages and heights of culms for better utilization. Journal of the Korean Wood Science and Technology 43(2): 145-155.

Maulana, S., Busyra, I., Fatrawana, A., Hidayat, W., Sari, R.K., Sumardi, I., Wistara, I.N.J., Lee, S.H., Kim, N.H., Febrianto, F. 2017. Effects of steam treatment on physical and mechanical properties of bamboo oriented strand board. Journal of the Korean Wood Science and Technology 45(6): 872-882.

Mustafa, M.T., Wahab, R., Sudin, M., Sulaiman, O., Kamal, N.A.M., Khalid, I. 2011. Anatomical and 
microstructures features of tropical bamboo Gigantochloa bring, G. Levis, G. scotechinii and G. wrayi. International Journal of Forest Soil and Erosion 1(1): 25-35.

Roh, J.K., Kim, J.K., Kim, S.I., Ra, J.B., Kim, Y.J., Park, S.J. 2004. Manufacture of wood veneer-bamboo zephyr composite board: I. Properties of bamboo zephyr and composite board made from moso, giant timber and hachiku bamboo. Journal of the Korean Wood Science and Technology 32(3): 42-51.

Troya, F.A., Xu, C. 2014. Plantation management and bamboo resource economics in china. Ciencia y Tecnología 7(1): 1-12.
Wahab, R., Mohamed, A., Mustafa, M.T., Hasan, A. 2009. Physical characteristics and anatomical properties of cultived bamboo (Bambusa vulgaris Schrad) culms. Journal of Biological Sciences 9(7): 753-759.

Widjaja, E.A. 2001. Identikit jenis-jenis bambu di Jawa. Puslitbang-Biologi-LIPI, Bogor, Indonesia.

Wu, W., Liu, Q., Zhu, Z., Shen, Y. 2015. Managing bamboo for carbon sequestration, bamboo stem and bamboo shoots. Small-scale Forestry 14: 233-243.

Zakikhani, P., Zahari, R., Sultan, M.T.H., Majid, D.L. 2017. Morphological, mechanical, and physical properties of four bamboo species. Bio Resources 12(2): 2479-2495. 